\title{
HER2 Overexpression in Retinoblastoma: A Potential Therapeutic Target?
}

\author{
David Cordeiro Sousa ${ }^{a, b}$ Pablo Zoroquiain ${ }^{c}$ Maria Eugenia Orellanad \\ Ana Beatriz Dias ${ }^{c}$ Evangelina Esposito ${ }^{c}$ Miguel N. Burnier Jr. ${ }^{c}$ \\ ${ }^{a}$ Department of Ophthalmology, Hospital de Santa Maria, and ${ }^{b}$ Centro de Estudos Ciências da Visão, Universidade \\ de Lisboa, Lisbon, Portugal; ' $M U H C$ - McGill University Ocular Pathology Laboratory, Montreal, QC, Canada; \\ dInstituto Anatomopatológico “Dr. José A. O’Daly”, Universidad Central de Venezuela, Caracas, Venezuela
}

\section{Keywords}

Retinoblastoma $\cdot$ Human epidermal growth factor receptor $2 \cdot$ Transmembrane protein · Anti-HER2 antibody · Immunohistochemistry

\begin{abstract}
Background: Retinoblastoma (RB) is the most common primary intraocular malignancy. Current therapies are associated with high morbidity in the short- and long-term. Human epidermal growth factor receptor 2 (HER2) is a transmembrane protein detected in $15-30 \%$ of breast cancers, but it has also been described in other malignancies. Recent$l y$, it has been claimed that a truncated version of this protein is expressed in $\mathrm{RB}$, responsive to directed therapies in vitro. We scored HER2 overexpression in RB tissue samples and discussed its potential clinical utility. Methods: HER2 overexpression was investigated using immunohistochemistry; the overexpression was evaluated with a score ranging from 0 to $3+$ according to the membranous staining pattern in archival formalin-fixed, paraffin-embedded RBs. Results: A total of 60 RB cases and a RB cell line (Y79) were considered. The mean age at enucleation was $31.6 \pm 31.5$ months. The mean time from diagnosis to enucleation was $11.8 \pm 11.2$ months (range 1-44). Five (8\%) cases were multifocal. HER2 overexpression was negative in all RB cases ( 49 cases scored 0 and 11 scored 1+) and in the Y79 cell line. Conclusions: Overall,
\end{abstract}

we were not able to demonstrate the overexpression of HER2. Further studies should clarify and better elucidate the potential role of HER2-targeted therapies in RB.

(c) 2017 S. Karger AG, Basel

\section{Introduction}

Retinoblastoma (RB) is a rare childhood cancer diagnosed in approximately 8,000 children each year worldwide [1]. It constitutes the most common primary intraocular malignancy, with an incidence rate of 1 in 16,00018,000 live births [1-3]. No geographical or racial variations in $\mathrm{RB}$ incidence were identified $[4,5]$. In low-income countries, RB is associated with low survival rates (45\%) when compared with middle- $(\sim 65 \%)$ and high-income countries ( $>95 \%)$; this is mainly due to limited health care access in these lower-income countries, which translates into delayed diagnosis and, ultimately, metastatic disease $[1,6]$. The treatment of choice is based on the likelihood of a cure, visual potential, and accessibility. Current options include enucleation, intravitreous chemotherapy, intravenous chemotherapy with focal laser or cryotherapy, intraarterial chemotherapy with focal therapy, and focal therapy alone (for small tumors) [6, 7]. However, their use must be weighed against associated, and potentially life-threatening, short- and long-term systemic complications [1,

\section{KARGER}

(c) 2017 S. Karger AG, Basel

E-Mail karger@karger.com

www.karger.com/oop
David Cordeiro Sousa

Departamento de Oftalmologia, Hospital de Santa Maria

Av. Prof Egas Moniz

PT-1649-035 Lisbon (Portugal)

E-Mail davidscsousa@medicina.ulisboa.pt 
Table 1. Pathology findings, $\mathrm{pT}$ staging, and classification

\begin{tabular}{|c|c|c|c|}
\hline Pathology findings & Stage & Score & $\begin{array}{l}\text { Cases, } \\
n(\%)\end{array}$ \\
\hline Tumor confined to eye (i.e., no optic nerve or choroidal invasion) & pT1 & 1 & $9(15.0)$ \\
\hline $\begin{array}{l}\text { Tumor invades the optic nerve head, but it does not extend past the lamina cribrosa, nor does it exhibit } \\
\text { focal choroidal invasion }\end{array}$ & $\mathrm{pT} 2 \mathrm{a}$ & 2 & $8(13.3)$ \\
\hline $\begin{array}{l}\text { Tumor invades the optic nerve head, but it does not extend past the lamina cribrosa and it exhibits focal } \\
\text { choroidal invasion }\end{array}$ & $\mathrm{pT} 2 \mathrm{~b}$ & 3 & $4(6.7)$ \\
\hline $\begin{array}{l}\text { Tumor invades the optic nerve past the lamina cribrosa (but it does not reach the surgical resection line), } \\
\text { or it exhibits massive choroidal invasion }\end{array}$ & pT3a & 4 & $15(25.0)$ \\
\hline $\begin{array}{l}\text { Tumor invades the optic nerve past the lamina cribrosa, but it does not reach the surgical resection line; } \\
\text { it also exhibits massive choroidal invasion }\end{array}$ & pT3b & 5 & $8(13.3)$ \\
\hline Tumor invades the optic nerve to the resection line, but no extraocular extension is identified & $\mathrm{pT} 4 \mathrm{a}$ & 6 & $4(6.7)$ \\
\hline Tumor invades the optic nerve to the resection line, and extraocular extension is identified & $\mathrm{pT} 4 \mathrm{~b}$ & 7 & $8(13.3)$ \\
\hline
\end{tabular}

6-8]. New treatment options are being developed to target specific RB genes and receptors, thus circumventing some of these potential safety issues $[9,10]$.

Human epidermal growth factor receptor 2 (HER2) is a transmembrane protein that is encoded by the HER2 proto-oncogene (also known as neu or c-erb B-2), mapped on chromosome 17q21 [11]. Its overexpression is mainly associated with breast cancer [12]. This finding has been explored therapeutically with good results using a HER2specific humanized monoclonal antibody, such as trastuzumab or lapatinib [13]. The identification of HER2 overexpression in other malignancies, such as ovarian cancer [14], gastric cancer [15], colon cancer [16], pancreatic cancer [17], and bladder cancer [18] has led to HER2directed therapeutic strategies for these neoplastic processes $[19,20]$.

Previous studies have suggested that HER2 would not be expressed in RB [21]. However, Seigel et al. [22] have recently claimed that significant HER2 immunoreactivity may be present in RB cell lines and in a small cohort of primary RB patients $(n=11)$. The authors suggested that a truncated version of the HER2 protein was present in $\mathrm{RB}$, and only a few anti-HER2 antibodies could recognize this version. Furthermore, this truncated version spared the trastuzumab binding site. In accordance with these findings, a truncated HER2 transmembrane protein has been proposed as a potential target in RB therapy [23]; however, due to its recent identification and limited characterization, there are no published data on therapies targeting HER2 in RB.
We aimed to study, describe, and analyze HER2 immunoexpression in a large cohort of primary RB cases as a potential novel therapeutic target.

\section{Materials and Methods}

A total of 60 formalin-fixed, paraffin-embedded primary RBs were gathered from the archives of the Henry C. Witelson Ocular Pathology Laboratory, McGill University (Montreal, QC, Canada). Age and sex data were obtained from histopathological reports. The tenets of the declaration of Helsinki were followed.

Tissue samples were hematoxylin and eosin stained, converted to digital slides, and evaluated for the presence of histopathological prognostic factors (ImageScope, version 12.1.0.5029; Aperio Technologies, Nussloch, Germany). Specifically, the following characteristics were evaluated: (i) growth, (ii) differentiation, (iii) optic nerve invasion, (iv) choroidal involvement, (v) anterior chamber invasion, and (vi) vitreous seeding. All cases in which these characteristics could not be accurately evaluated were excluded. According to the morphological findings, a pathological score (1-7) was calculated according to the RB pathological classification system, pTNM (Table 1) [24].

In order to study the Y79 RB cell line, cell culture and cell block were performed, as previously described $[25,26]$.

Immunohistochemistry (IHC) was performed using the Ventana BenchMark LT (Ventana Medical System Inc., Tucson, AZ, USA). The fully automated processing of barcode-labeled slides included baking the slides, using solvent-free deparaffinization, and performing $\mathrm{CC} 1$ (Tris/EDTA buffer $\mathrm{pH}$ 8.0) antigen retrieval. In order to achieve the desired selective membranous staining, the antibody concentration was titrated using amplified HER2, as confirmed by fluorescent in situ hybridization (FISH) mammary carcinoma and an HER2 score of $3+$ by IHC (Fig. 1). 

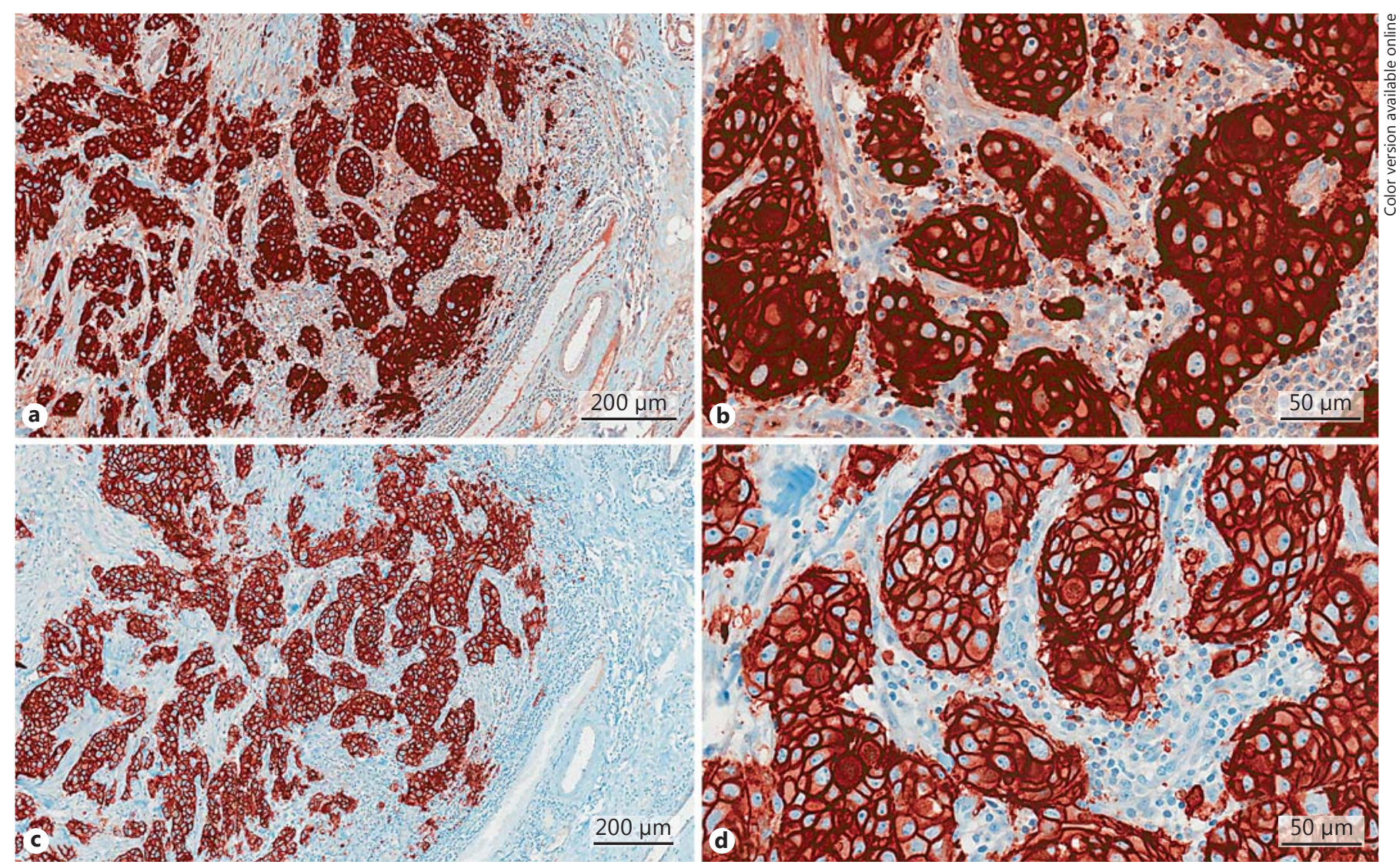

Fig. 1. HER2-positive mammary carcinoma used for antibody titration. a Diffuse staining featuring a strong cytoplasmic expression and stromal background (b, inset), using a 1:100 dilution of the antibody. $\mathbf{c}$, d Positive and selective membrane staining, using a 1:200 dilution of the antibody. HER2, human epidermal growth factor receptor 2 .

Slides were incubated with a $1 / 200$ dilution of the monoclonal anti-tyrosine kinase-type cell-surface receptor HER2 antibody, which was produced in rabbit (\#HPA001383; Sigma-Aldrich Canada Co., Oakville, ON, Canada) for $30 \mathrm{~min}$ at $37^{\circ} \mathrm{C}$, followed by the application of a biotinylated secondary antibody $\left(8 \mathrm{~min}, 37^{\circ} \mathrm{C}\right)$, and an avidin/streptavidin enzyme conjugate complex $(8 \mathrm{~min}$, $37^{\circ} \mathrm{C}$ ). Finally, the antibody was detected by DAB chromogenic substrate and counterstained with hematoxylin. As a positive control, HER2-positive mammary carcinoma tissue was used in each run. The primary antibody was omitted for negative controls.

The digital slides were evaluated and classified with a digital software using a score of 0 (i.e., negative) to $3+$ (i.e., positive), similar to the method used for breast carcinoma [27]. This 4-level scoring system corresponds to the following characteristics: 0 for the absence of membranous staining; 1 for faint, partial membranous staining in $>10 \%$ of cancer cells, with rare or absent cells exhibiting circumferential staining; 2 for weak, circumferential membranous staining in $>10 \%$ of cells; and 3 for intense circumferential membranous staining in $>10 \%$ of cells. Absent or weakly stained cells ( 0 or $1+$, respectively) equate to $<100,000$ receptors and no detectable amplification of the HER2 gene. Strong, circumferential staining $(3+)$ correlates with a level of expression that is almost always associated with HER2 amplification [28].

\section{Results}

\section{Overview}

A total of $60 \mathrm{RB}$ specimens obtained from 60 patients (66.7\% of which were males) were immunostained in this study. The mean age at enucleation was $31.6 \pm 31.5$ months (range: $3-192$ ) and the mean time to enucleation was $11.8 \pm 11.2$ months (range: $1-44$ ).

\section{Morphological Characteristics}

Table 1 summarizes the pathological classification of our sample. Among all RB cases in this study, 7 (11.7\%) were well differentiated and $37(61.7 \%)$ were poorly differentiated. Regarding growth, almost all cases $(91.7 \%)$ exhibited both endophytic and exophytic patterns. In 15 $(25 \%)$ cases, there was invasion of the anterior chamber. Involvement of the choroid and the optic nerve by $\mathrm{RB}$ cells was identified in $41(68.3 \%)$ and 48 (80\%) cases, respectively. Vitreous seeding was recognized in 40 (66.7\%)
Ocul Oncol Pathol 2017;3:210-215 DOI: $10.1159 / 000455871$
Sousa/Zoroquiain/Orellana/Dias/ Esposito/Burnier Jr. 


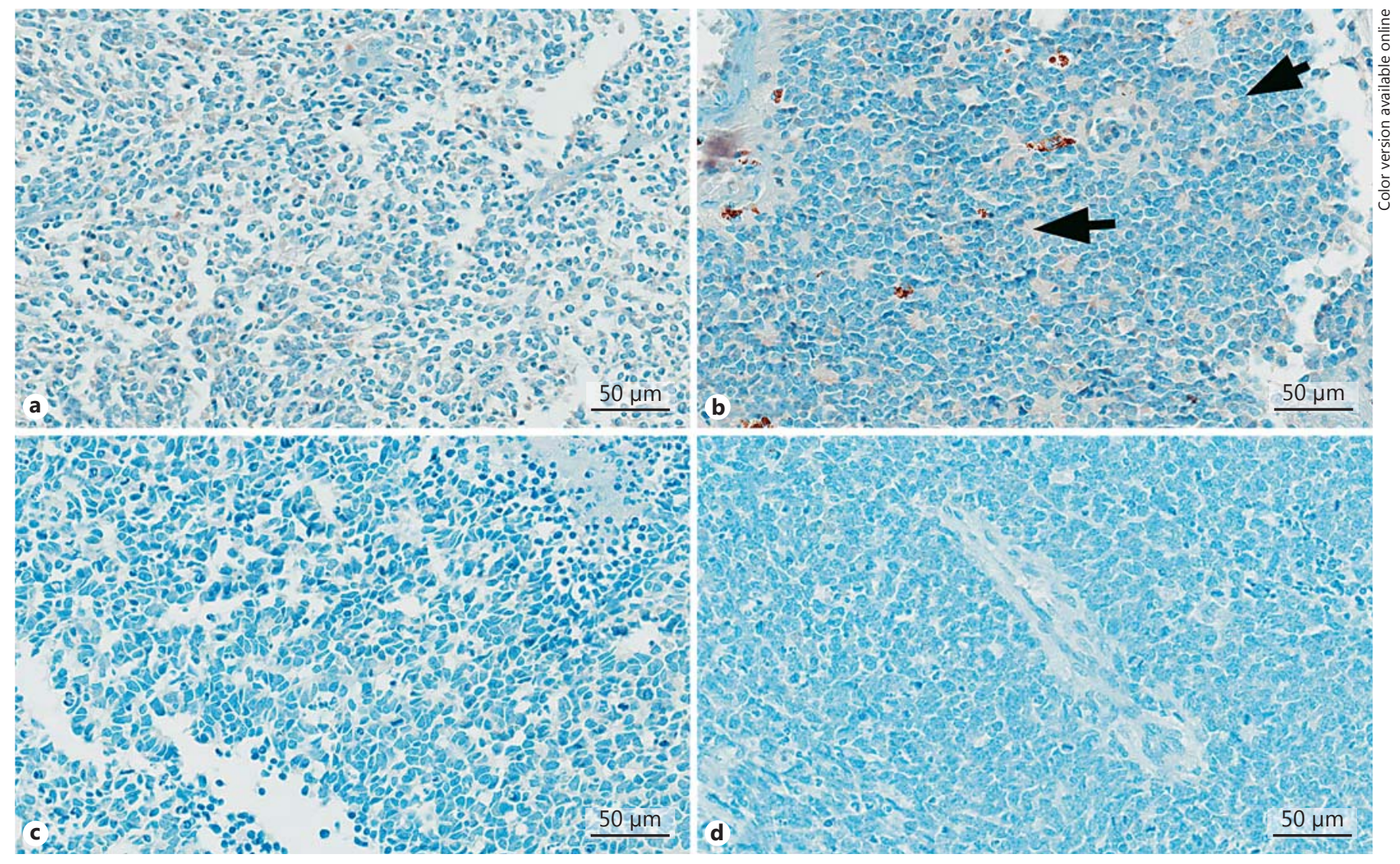

Fig. 2. RB tissue samples with HER 2 immunostaining. a, b Poorly and well-differentiated areas showing no staining. c, d Poorly and well-differentiated areas classified with an HER2 score of 1+ (i.e., negative for HER2). RB, retinoblastoma; HER2, human epidermal growth factor receptor 2.

of our tissue samples. Furthermore, $5(8 \%)$ cases were multifocal.

\section{HER2 Immunoreactivity}

A HER2 1+ score was identified in $11(18.3 \%)$ cases. In the remaining cases, membrane staining of the RB tissue samples was also negative (score $=0$ ) (Fig. 2). Furthermore, we used the Y79 cell line to confirm these findings. This cell line showed no HER2 immunoreactivity (score $=0$ ), with proper control slides staining (Fig. 3). Positive controls stained positively with an HER2 score of $3+$ on each machine run and using a fully automated process (Fig. 1).

\section{Discussion}

Although some conventional therapies targeting multiple pathways had already led to some important successes in medicine [29], highly selective therapies are now at the frontline of the drug discovery industry since their adverse events can be significantly reduced [30]. The first step in drug discovery is the identification of a novel drug target. As is the case for the HER2 protein with trastuzumab, other extracellular proteins and cell-surface receptors are potentially good targets for selective biologic therapies. The idea is to guide the cytotoxic response to a selected location in the disease tissue, where the antigen is expressed [30]. In breast cancer, the success of trastuzumab therapy significantly improved the disease-free and overall survival of women with tumors overexpressing HER2 in both early and metastatic breast cancer [31].

Most commonly, HER2 testing in clinical practice is done either using FISH to directly quantify the HER2 gene copy number, or by IHC analysis, with confirmatory FISH if necessary [32].

As previously stated, Seigel et al. [22] have recently claimed that there is a truncated version of this transmembrane protein in $\mathrm{RB}$ tissue samples, as recognized by 


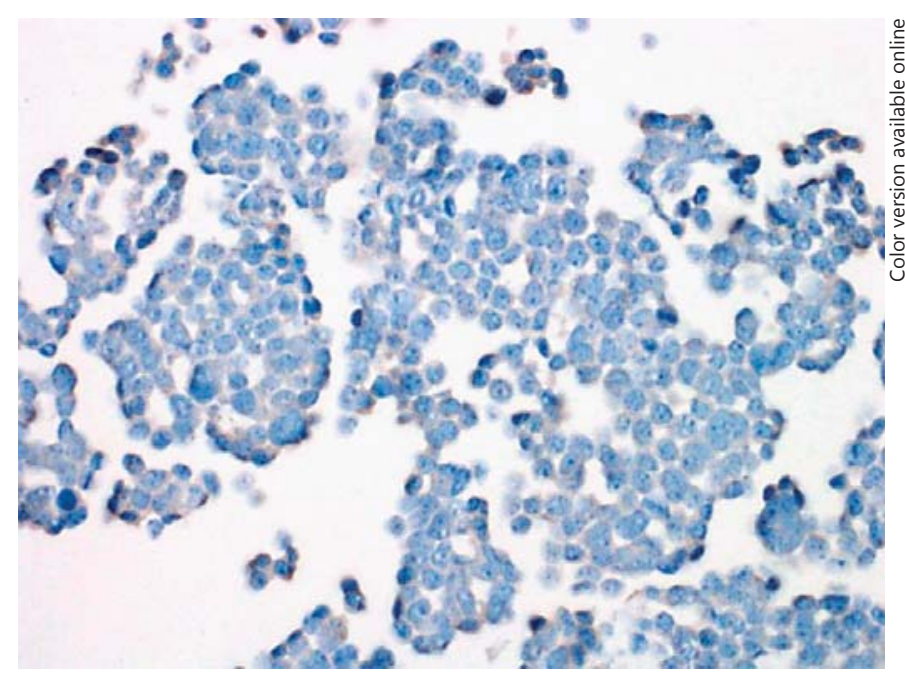

Fig. 3. RB Y79 cell line. No HER2 overexpression was identified (score $=0)$. RB, retinoblastoma; HER2, human epidermal growth factor receptor 2 .

some antibodies - including trastuzumab. These authors studied HER2 expression in various cell lines and in 11 tissue samples, which were scored from 0 to $3+$. According to the guidelines for HER2 IHC scoring in both breast and gastric cancer, a score of 0 or $1+$ is considered negative, a score of $2+$ is considered equivocal, and a score of $3+$ is considered positive. Only a $3+$ positive score is an indication for the use of HER2-directed therapies [27]. In their study, 3 (27\%) of the tissue samples had a HER2 $3+$ score (i.e., positive), 5 ( $46 \%$ ) had a $2+$ score (i.e., equivo$\mathrm{cal})$, and the remaining 3 (27\%) were classified with a $1+$ score (i.e., negative) [22].

Thus, it would be important to better study and clarify these findings using a larger sample in order to elucidate the potential clinical utility of trastuzumab and other anti-HER2 therapies in RB cases. Yet, our study that investigated a large and heterogeneous sample of RB tissue samples showed negative HER2 immunostaining in all cases. Of note, positive controls stained positively with an HER2 score of $3+$ on each machine run and using a fully automated process (Fig. 1). These results are in accordance with previously published data, in which HER2 immunoreactivity was not found [21]. However, as we were expecting similar findings, we comprehensively reviewed our methodology. The tissue sample preparation and IHC were performed in a similar fashion. Also, the antibody used was the same (Sigma-Aldrich \#HPA001383). This anti-HER2 antibody binds to the intracellular protein domain and detects the truncated HER2 protein, which Seigel et al. [22] postulate to be present in $\mathrm{Rb}$. We used HER2-positive mammary carcinoma as a positive control. In order to achieve the desired selective membranous staining, the antibody concentration was titrated as described in the Materials and Methods section, and a dilution of 1:200 was used (Fig. 1c, d). Notably, this dilution is 10 times lower than the one used by researchers who suggested positive HER2 immunoexpression in RB [22]. Since in this IHC study, we aimed to specifically stain a transmembrane protein, it would be crucial to accurately define the antibody concentration and protocol as described in the Materials and Methods section. Therefore, we believe our findings are not falsely negative, as the control slide was clearly positively stained (score $3+$ ) and all concurrent $\mathrm{Rb}$ slides were negative for HER2. On the contrary, in Figure 1a of Seigel et al.'s study [22], one may observe significant background staining, with unclear cellular membrane definition. The fact that these may correspond to false positive results should be clarified in future studies.

As presented in the Results section, the RB samples from the Henry C. Witelson Ocular Pathology Laboratory displayed a full spectrum of morphological characteristics, such as the presence/absence of the optic nerve, as well as choroidal and extraocular invasion (Table 1). Moreover, and in order to validate the immunoreactivity of the tissue, we have recently performed studies for other targets using the same RB samples and IHC methodology in our laboratory, in which positive immunoexpression was obtained [9]. It would be unlikely that none of the cases analyzed, which were fixated using buffered formalin within different time frames, were all negative for HER2 overexpression.

Our study has several limitations. In their study, Seigel et al. [22] used 2 different antibodies, both of which yielded positive findings. We used only 1 of these antibodies, as previously described. However, since we comprehensively reviewed the IHC methodology and antibody titration, the use of the second antibody was expected to lead us to the same negative immunostaining. For future studies, it would be interesting to separately group hereditary and nonhereditary RB; however, genetic data were not accessible from the registry. Lastly, even though FISH is the gold standard method used, we decided to design this study based on IHC results, so our findings would be comparable with the recent findings of RB HER2 expression. However, the only way to definitely conclude if HER2 is overexpressed is to study with FISH. We plan to perform FISH in future studies, which would help to clarify the HER2 status in RB. 


\section{Conclusion}

Overall, our sample of RB tissue samples was negative for HER2 overexpression. These results do not reproduce the recent findings of HER2 immunoexpression in RB. Considering our translational approach, and with respect to clinical utility, a novel and good drug target for RB should not be susceptible to such variability. Further studies would clarify and better elucidate the potential role of HER2-targeted therapies in RB.

\section{Acknowledgments} Prep.

English language editing of this study was provided by Journal

\section{Disclosure Statement}

None of the authors have any potential conflicts of interest or financial supports to disclose regarding this work.

\section{References}

1 Dimaras H, Corson TW, Cobrinik D, White A, Zhao J, Munier FL, Abramson DH, Shields CL, Chantada GL, Njuguna F, Gallie BL: Retinoblastoma. Nat Rev Dis Primers 2015;1: 15021.

2 Dimaras H, Kimani K, Dimba EAO, Gronsdahl P, White A, Chan HSL, Gallie BL: Retinoblastoma. Lancet 2012;379:1436-1446.

3 Kivelä T: The epidemiological challenge of the most frequent eye cancer: retinoblastoma, an issue of birth and death. $\mathrm{Br} \mathrm{J}$ Ophthalmol 2009;93:1129-1131.

4 Broaddus E, Topham A, Singh AD: Incidence of retinoblastoma in the USA : 1975-2004. Br J Ophthalmol 2009;93:21-23.

5 Krishna SM, Yu GP, Finger PT: The effect of race on the incidence of retinoblastoma. J Pediatr Ophthalmol Strabismus 2009;46:288-293.

6 Abramson DH, Shields CL, Munier FL, Chantada GL: Treatment of retinoblastoma in 2015: agreement and disagreement. JAMA Ophthalmol 2015;133:1-7.

7 Shields CL, Shields JA: Retinoblastoma management: advances in enucleation, intravenous chemoreduction, and intra-arterial chemotherapy. Curr Opin Ophthalmol 2010;21: 203-212.

8 Tamboli D, Topham A, Singh N, Singh AD: Retinoblastoma: a SEER dataset evaluation for treatment patterns, survival, and second malignant neoplasms. Am J Ophthalmol 2015;160:953-958.

9 Sanft DM, Worme MD, Rielo de Moura L, Zoroquiain P, Fernandes BF, Antecka E, Burnier MN Jr: Immunohistochemical analysis of PDGFR- $\alpha$, PDGFR- $\beta$ and $c-A b l$ in retinoblastoma: potential therapeutic targets. Ophthalmic Res 2016;55:159-162.

10 Orellana ME, Quezada C, Maloney SC, Antecka E, Balazsi M, Burnier MN: Expression of SIRT2 and SIRT6 in retinoblastoma. Ophthalmic Res 2015;53:100-108.

11 Yarden Y: Biology of HER2 and its importance in breast cancer. Oncology 2001; 61(suppl 2):1-13.

12 Iqbal N, Iqbal N: Human epidermal growth factor receptor 2 (HER2) in cancers: overexpression and therapeutic implications. Mol Biol Int 2014;2014:1-9.
13 Arteaga CL, Sliwkowski MX, Osborne CK, Perez EA, Puglisi F, Gianni L: Treatment of HER2-positive breast cancer: current status and future perspectives. Nat Rev Clin Oncol 2011;9:16-32.

14 Färkkilä A, Andersson N, Bützow R, Leminen A, Heikinheimo M, Anttonen M, Unkila-Kallio L: HER2 and GATA4 are new prognostic factors for early-stage ovarian granulosa cell tumor - a long-term follow-up study. Cancer Med 2014;3:526-536.

15 Boku N: HER2-positive gastric cancer. Gastric Cancer 2014;17:1-12.

16 Blok EJ, Kuppen PJK, van Leeuwen JEM, Sier CFM: Cytoplasmic overexpression of HER2: a key factor in colorectal cancer. Clin Med Insights Oncol 2013;7:41-51.

17 Ata A, Polat A, Serinsöz E, Sungur MA, Arican A: Prognostic value of increased her2 expression in cancers of pancreas and biliary tree. Pathol Oncol Res 2014;21:831-838.

18 Krüger S, Weitsch G, Büttner $\mathrm{H}$, Matthiensen A, Böhmer T, Marquardt T, Sayk F, Feller AC, Böhle A: HER2 overexpression in muscle-invasive urothelial carcinoma of the bladder: prognostic implications. Int J Cancer 2002; 102:514-518.

19 Baselga J: Treatment of HER2-overexpressing breast cancer. Ann Oncol 2010;21(suppl 7):vii36-vii40.

20 Moussaid Y, Chargari C, Mansouri M, Bonardel G, Houlgatte A, Vedrine L: Trastuzumab therapy in metastatic bladder carcinoma: the proof of concept. J Cancer Res Ther 2014;2: 128-131.

21 Bösch D, Pache M, Simon R, Schraml P, Glatz K, Mirlacher M, Flammer J, Sauter G, Meyer $\mathrm{P}$ : Expression and amplification of therapeutic target genes in retinoblastoma. Graefes Arch Clin Exp Ophthalmol 2005;243:156162.

22 Seigel GM, Sharma S, Hackam AS, Shah DK: HER2/ERBB2 immunoreactivity in human retinoblastoma. Tumour Biol 2016;37:61356142 .

23 Zagozdzon R, Gallagher WM, Crown J: Truncated HER2: implications for HER2-targeted therapeutics. Drug Discov Today 2011;16: 810-816.
24 Edge SE, Byrd DR, Compton CC, Fritz AG Green FL, Trotti A: Retinoblastoma; in American Joint Committee on Cancer. Cancer Staging Manual, ed 7. New York, Springer, 2010, pp 561-568.

25 Jain D, Mathur SR, Iyer VK: Cell blocks in cytopathology: a review of preparative methods, utility in diagnosis and role in ancillary studies. Cytopathology 2014;25:356-371.

26 de Moura LR, Marshall J-C, Di Cesare S, Fernandes BF, Antecka E, Burnier MN: the effect of imatinib mesylate on the proliferation, invasive ability, and radiosensitivity of retinoblastoma cell lines. Eye (Lond) 2013;27:9299.

27 Wolff AC, Hammond MEH, Schwartz JN, Hagerty KL, Allred DC, Cote RJ, Dowsett M, Fitzgibbons PL, Hanna WM, Langer A, McShane LM, Paik S, Pegram MD, Perez EA, Press MF, Rhodes A, Sturgeon C, Taube SE, Tubbs R, Vance GH, van de Vijver M, Wheeler TM, Hayes DF: American Society of Clinical Oncology/College of American Pathologists guideline recommendations for human epidermal growth factor receptor 2 testing in breast cancer. J Clin Oncol 2007;25:118-145.

28 Ross JS, Slodkowska EA, Symmans WF, Pusztai L, Ravdin PM, Hortobagyi GN: The HER2 receptor and breast cancer: ten years of targeted anti-HER-2 therapy and personalized medicine. Oncologist 2009;14:320-368.

29 Hopkins AL: Network pharmacology: the next paradigm in drug discovery. Nat Chem Biol 2008;4:682-690.

30 Gashaw I, Ellinghaus P, Sommer A, Asadullah $\mathrm{K}$ : What makes a good drug target? Drug Discovery Today 2012;17(suppl):S24-S30.

31 Slamon DJ, Leyland-Jones B, Shak S, Fuchs H: Use of chemotherapy plus a monoclonal antibody against Her2. N Engl J Med 2001;344: 783-792.

32 Ballinger TJ, Sanders ME, Abramson VG: Current HER2 testing recommendations and clinical relevance as a predictor of response to targeted therapy. Clin Breast Cancer 2015;15: 171-180. 